\title{
Efficacy of Probiotics to Reduce Nosocomial Infection and Feeding Intolerance in Hospitalized Low Birth Weight Babies
}

\author{
MM HAQUE $^{\mathrm{a}}, \mathrm{S}^{\mathrm{SFROZA}}{ }^{\mathrm{b}}, \mathrm{AH}^{\mathrm{MOLLAH}}{ }^{\mathrm{c}}$
}

\begin{abstract}
Summary:
Background and objective: Neonatal sepsis is associated with increased mortality and morbidity of newborns. Moreover, inability to tolerate enteral feeding contributes to prolonged hospital stay and nosocomial sepsis. Probiotics confers health benefit to host by altering the gut environment. This study aimed at determining the efficacy of probiotics in reducing nosocomial sepsis and feeding intolerance in hospitalized low birth-weight infants.
\end{abstract}

Methods: A quasi experimental clinical trial to compare between newborn infants getting probiotics along with breast milk (experimental group) with those getting breast milk only (non experimental group). Study was conducted from June to December 2013 with a total of 49 newborns, weighing 1000 to $2000 \mathrm{gm}$.

Results: In weight category 1000-1250 gm, 15.8\% developed culture proven sepsis in probiotics/experimental group $(n=9)$ and $10.5 \%$ in breast milk/non experimental group $(n=10)$; $p$ value was 0.655 . Feeding intolerance was developed in $10.6 \%$ of the probiotics group and $31.5 \%$ of breast milk group, $p$ value was not significant but the mortality was significantly lower among the probiotics group

Introduction:

Nosocomial infection (also referred to as late-onset neonatal sepsis or health care associated infection) in the neonatal intensive care units (NICU) is associated with morbidity and mortality, prolonged hospitalization, and increased medical costs ${ }^{1}$. The nosocomial infection

a. Dr. Md. Mozammel Haque, Medical Officer, 250 Bedded TB Hospital, Shyamoli, Dhaka.

b. Professor Syeda Afroza, Ex professor \& head of Pediatrics, Saheed Sohrawardi Medical College Hospital, Dhaka.

c. Professor Abid Hossain Mollah, Ex professor \& head of Pediatrics, Dhaka Medical College Hospital, Dhaka.

Address of Correspondence: Dr. Md. Mozammel Haque, Medical Officer, 250 Bedded TB Hospital, Shyamoli, Dhaka. Email: mmhaque16rmc@yahoo.com, Cell: 8801711148068.

Received: 25 Oct. 2016

Accepted: 23 Jan. 2018 i.e., 5.3\% in probiotics group Vs $42.1 \%$ in breast milk group (p 0.018). Between weight range of 1250-1500 gm, sepsis and feeding intolerance showed no significant differences (p value $0.305 \& 0.305$ respectively) but mortality differed significantly (0\% probiotics group Vs $20 \%$ breast milk group; p 0.043). In weight range 1500-2000 gm, the result was not statistically significant for sepsis (p value 0.292), feeding intolerance ( $p$ value 0.292) and mortality (p value 0.292). Mortality was significantly lower in two weight categories (1000-1250 gm \& 1250-1500 gm) and hence the overall result showed significant difference in the statistical analysis ( $p$ value 0.001).There were no differences either in nosocomial sepsis or feeding intolerance between the probiotics group and the breast milk group.

Conclusion: Probiotics does not have any impact in reducing nosocomial infection and feeding intolerance but the use of probiotics seems to reduce mortality especially in the lower weight category.

Key words: Probiotics, nosocomial sepsis, feeding intolerance.

(J Bangladesh Coll Phys Surg 2018; 36: 48-52) DOI: http://dx.doi.org/10.3329/jbcps.v36i2.36065

rate in the NICUs has increased over the past decades. About 6.2 to $33 \%$ of all neonates admitted to the NICU developed nosocomial infection ${ }^{2}$. Of all the very low birth weights (VLBW $<1500 \mathrm{gm}$ ) infants, $21 \%$ developed at least one episode of culture proven sepsis ${ }^{3}$. The most common organisms causing nosocomial infection in neonates include Staphylococcus, Escherichia coli, Klebsiella, and Candida. Coagulasenegative staphylococcus (CoNS) is responsible for almost half of the late-onset sepsis ${ }^{3,4}$.

Feeding intolerance is one of the most significant contributors to growth failure in low birth-weight preterm infants ${ }^{5}$. The inability to sustain enteral feedings contributes to extended periods of hospital stay, dependency on parenteral nutrition, nosocomial sepsis and this forms a vicious cycle ultimately leads 
to a very high mortality ${ }^{5}$. Establishing and tolerating adequate enteral nutrition is difficult due to the immaturity of the VLBW infants' gastrointestinal system; however, it is important for their normal growth, infection resistance, and long-term cognitive and neurologic development ${ }^{5}$.

Probiotics are defined by the World Health Organization as "live microorganisms, which when administered in an adequate amount confer a health benefit to the host" $\mathrm{t}$. The most frequently used probiotics are lactobacillus and Bifidobacterium. Potential mechanisms by which probiotics may protect high-risk infants from developing NEC and sepsis include increased barrier to migration of the bacteria and their products across the mucosa, competitive exclusion of potential pathogens, modification of host response to microbial products, augmentation of IGA mucosal responses, enhancement of enteral nutrition that inhibits the growth of pathogens, and up-regulation of immune responses ${ }^{6}$. Probiotics has an additional effect on feeding intolerance through the following mechanisms-breaking down food for digestion, producing the lactase enzyme (which helps digest milk sugar), boosting the immune system ${ }^{7}$, increasing bowel movement ${ }^{8}$. Mihatsch et al. reported that some probiotics were beneficial in relation to reduction of severe NEC and reduction of mortality 9 but here there were no convincing benefits with regard to prevention of nosocomial sepsis. The authors concluded that there is insufficient evidence to recommend routine probiotics in preterm infants.

In this study prophylactic probiotics were used for preterm LBW newborns with the aim to observe the efficacy in reducing nosocomial infection and feeding intolerance.

Materials and Methods: It was a quasi experimental clinical trial conducted at Neonatal Care Unit (NCU) of Sir Salimullah Medical College \& Mitford Hospital from a period of June to December 2013 involving 49 VLBW infants selected sequentially. The newborns with the following criteria were enrolled into this study: low birth-weight (1000-2000gm), hemodynamically stable, without any evidence of sepsis; birth asphyxia and respiratory distress syndrome were included when the newborns were stable to take the enteral feed. Babies were included in this study within 24 hours of starting enteral feeding. Newborns having following criteria were excluded from the study: any surgical condition like intestinal obstruction, perforation, gastroschisis, omphalocele, congenital diaphragmatic hernia, imperforate anus, cleft lip and palate, major congenital heart disease and in whom feeding started with formula milk.

After fulfillment of inclusion criteria, a total of $50 \mathrm{LBW}$ infant (1000-2000gm) were enrolled among which 25 were given probiotics along with expressed breast milk and 25, breast milk only. To avoid disparities in weight category, equal number of participants in both group in the weight between 1000-1250gm, 1250-1500gm \& 1500-2000gm were taken. Among 25 babies in the probiotics group there was one dropout because one mother refused to continue probiotics, so 24 enrolled newborn were followed as probiotics group. The probiotics group received a probiotics mixture containing six live microorganisms (Bifidobacteria infantis, Bifidobacteria bifidum, Bifidobacteria longum, Lactobacillus acidophilus, Lactobacillus casein, Lactobacillus rhamnosus, Streptococcus thermopiles, Bifidobacteria brave, Bifidobacteria infantis and Lactobacillus bulgaricus). This was commercially available as 'Protexin Restore'. One sachet of 'Protexin Restore' contains two gm powder in which $1 \times 10^{10} \mathrm{CFU}$ bacteria is present in each gm; dissolving this powder in four $\mathrm{ml}$ of expressed breast milk, $0.5 \mathrm{ml}$ (equivalent to $0.25 \mathrm{gm}$ ) twice daily was given until discharge of the baby. Feeding intolerance was monitored based on vomiting (altered milk, bile or blood stained), abdominal distension (abdominal girth $\geq 2 \mathrm{~cm}$ from baseline, measured at the level of the umbilicus), and increased gastric residuals ( $>50 \%$ of previous feed). All enrolled babies were investigated for the confirmation of sepsis by doing blood culture at least 48 hours after probiotics administration in probiotics group and 48 hours after the hospital stay in the breast milk group. Along with these parameters weight gain was observed by daily weight measurement during the data collection process. The lengths of total hospital stay and overall mortality were observed and recorded. Data were collected on a pretested structured case record form and analysed by using SPSS version 16.

\section{Results:}

A total of 49 preterm LBW newborns were included as study group according to inclusion criteria. Among the probiotics group $62.5 \%$ were female newborns whereas $32 \%$ among the breast milk group. Fifty percent of the newborns in the probiotics group and $20 \%$ in the breast milk group were delivered by lower uterine caesarean section (LUCS). 
Among 24 babies in the probiotics group 12.5\% developed culture proven sepsis and among the 25 in the breast milk group 20\% developed sepsis during their hospital stay. The difference was not statistically significant, $\mathrm{p}$ value 0.460 (Table-1).

No significant differences were noted in feeding intolerance between the probiotics group and the breast milk group e.g. (altered vomitus $0 \%$ Vs $12 \%$; altered vomitus, abdominal girth \& gastric residual $4.2 \% \mathrm{Vs}$
$8 \%$ between probiotics \& breast milk group respectively (Table-2).

In the probiotics group $4.2 \%$ newborns died and $52 \%$ died in the breast milk group. This difference was statistically significant, p value 0.001(Table-3).

The mean hospital stay was $10.33 \pm 5.40$ days in the probiotics group and $7.72 \pm 5.41$ days in the breast milk group and the difference was not statistically significant, $\mathrm{p}$ value 0.097 (Table-4).

Table-I

Rate of culture proven nosocomial sepsis among the studied babies $(n=49)$

\begin{tabular}{|c|c|c|c|c|c|c|c|c|}
\hline \multirow[t]{2}{*}{$\begin{array}{l}\text { Nosocomial } \\
\text { sepsis }\end{array}$} & \multicolumn{2}{|c|}{$\begin{array}{l}\text { Experimental group } \\
\text { given probiotics along } \\
\text { with breast milk }\end{array}$} & \multicolumn{2}{|c|}{$\begin{array}{l}\text { Non experimental } \\
\text { group given breast } \\
\text { milk only }\end{array}$} & \multicolumn{2}{|c|}{ Total } & \multirow{2}{*}{\multicolumn{2}{|c|}{ P value Odds Ratio }} \\
\hline & No & $\%$ & No & $\%$ & No & $\%$ & & \\
\hline Blood C/S Positive & 3 & $12.5 \%$ & 5 & $20.0 \%$ & 8 & $16.3 \%$ & 0.460 & 0.57 \\
\hline Blood C/S Negative & 21 & 87.5 & 20 & $80.0 \%$ & 41 & $83.7 \%$ & 0.898 & 1.75 \\
\hline
\end{tabular}

Test of significance was done by Fisher's Exact Test.

Table-II

\section{Rate of feeding intolerance among the studied babies $(n=49)$}

\begin{tabular}{|c|c|c|c|c|c|c|c|c|}
\hline \multirow[t]{2}{*}{ Feeding Intolerance } & \multicolumn{2}{|c|}{$\begin{array}{l}\text { Experimental } \\
\text { group given } \\
\text { probiotics along } \\
\text { with breast milk }\end{array}$} & \multicolumn{2}{|c|}{$\begin{array}{c}\text { Non experimental } \\
\text { group given breast } \\
\text { milk only }\end{array}$} & \multicolumn{2}{|c|}{ Total } & \multirow[t]{2}{*}{ pvalue } & \multirow[t]{2}{*}{ OddsRatio } \\
\hline & No & $\%$ & No & $\%$ & No & $\%$ & & \\
\hline Altered vomitus & 0 & $.0 \%$ & 3 & $12.0 \%$ & 3 & $6.1 \%$ & 0.059 & \\
\hline $\begin{array}{l}\text { Abdominal girth }(>2 \mathrm{~cm} \\
\text { from base line) }\end{array}$ & 1 & $4.2 \%$ & 1 & $4.0 \%$ & 2 & $4.1 \%$ & 1.00 & 1.05 \\
\hline $\begin{array}{l}\text { Altered vomitus + } \\
\text { Gastric residual }\end{array}$ & 0 & $.0 \%$ & 1 & $4.0 \%$ & 1 & $2.0 \%$ & 0.263 & \\
\hline $\begin{array}{l}\text { Abdominal girth + } \\
\text { Gastric Residual }\end{array}$ & 0 & $.0 \%$ & 1 & $4.0 \%$ & 1 & $2.0 \%$ & 0.263 & \\
\hline $\begin{array}{l}\text { Altered vomitus }+ \\
\text { Abdominal girth }+ \\
\text { Gastric residual }\end{array}$ & 1 & $4.2 \%$ & 2 & $8.0 \%$ & 3 & $6.1 \%$ & 0.439 & 0.51 \\
\hline No intolerance & 22 & $91.7 \%$ & 17 & $68.0 \%$ & 39 & $79.6 \%$ & 0.396 & 5.20 \\
\hline
\end{tabular}

Test of significance was done by Fisher's Exact Test. 
Table-III

\begin{tabular}{|c|c|c|c|c|c|c|c|c|}
\hline \multicolumn{9}{|c|}{ Mortality pattern } \\
\hline \multirow[t]{2}{*}{ Life Status } & \multicolumn{2}{|c|}{$\begin{array}{l}\text { Experimental group } \\
\text { given probiotics } \\
\text { along with breast milk }\end{array}$} & \multicolumn{2}{|c|}{$\begin{array}{l}\text { Non experimental } \\
\text { group given } \\
\text { breast milk only } \\
\end{array}$} & \multicolumn{2}{|c|}{ Total } & \multirow[t]{2}{*}{ pvalue } & \multirow[t]{2}{*}{ OddsRatio } \\
\hline & No & $\%$ & No & $\%$ & No & $\%$ & & \\
\hline Alive & 23 & $95.8 \%$ & 12 & $48.0 \%$ & 35 & $71.4 \%$ & 0.058 & 24.71 \\
\hline Dead & 1 & $4.2 \%$ & 13 & $52.0 \%$ & 14 & $28.6 \%$ & 0.001 & 0.04 \\
\hline
\end{tabular}

Test of significance done by Fisher's Exact Test.

Table-IV

Total hospital stay (in days) of studied babies $(n=49)$

\begin{tabular}{lccc} 
Study Group & Mean \pm SD ( Days) & t & P value \\
\hline Experimental group given probiotics along with breast milk & $10.33 \pm 5.40$ & 1.69 & 0.097 \\
Non experimental group given breast milk only & $7.72 \pm 5.41$ & \\
\hline
\end{tabular}

Test of significance was done by " $t$ " test.

\section{Discussion:}

In this study, 24 newborns were in the probiotics group, and 25 were in the breast milk group. No significant differences in baseline characteristics in between groups were observed except mean gestational age, and mean age of starting feeding. Mean age of starting feeding in the probiotics group was $2.6 \pm 0.9$ days and in the breast milk group, it was $3.03 \pm 0.85$ days. It was consistent with previous studies by Samanta $\mathrm{M}$ et al ${ }^{10}$ and Dani $\mathrm{C}$ et $\mathrm{al}^{11}$. In this study, probiotics was used in a twice daily dose until the baby was discharged from NICU. Samanta $\mathrm{M}$ et al ${ }^{10}$ used probiotics twice daily until discharge or 60 days.

The cumulative results revealed no statistically significant differences in the occurrence of nosocomial sepsis between the probiotics group and the breast milk group ( $p$ value 0.460 ) which was consistent with the results of other studies done by Dani $\mathrm{C}$ et $\mathrm{al}^{11}$ and Deshpande $\mathrm{G}$ et $\mathrm{al}^{9}$. In a meta-analysis by Deshpande $\mathrm{G}$ et $\mathrm{al}^{9}$, the risk of blood culture positive sepsis (six trials, $\mathrm{n}=1355$ ) did not differ significantly between probiotics and control group (RR 0.94, 95\% CI: 0.74-1.20) which was consistent with the present study.

Feeding intolerance was analysed in the study population and revealed no differences in between groups. Hu XY et $\mathrm{al}^{12}$ in their study showed that Probiotics reduced the incidence of feeding intolerance in LBW premature infants (4\%. Vs 14\%; $\mathrm{p}<0.01$ ) that is not consistent with the present study.

Number of death was significantly lower in the probiotics group than in the breast milk group, which was consistent with the results of studies by Samanta $\mathrm{M}$ et $\mathrm{al}^{10}$ and $\mathrm{Lin} \mathrm{CH}$ et $\mathrm{al}^{13}$. A meta-analysis by Deshpande $\mathrm{G}$ et $\mathrm{al}^{9}$ revealed significantly reduced mortality by probiotics use (RR $0.47,95 \%$ CI: 0.30 0.73 ) which was comparable to this study result. One possible explanation for this better outcome was the higher female inclusion in the probiotics group as genetically female do better due to double ' $\mathrm{X}$ ' chromosome. ${ }^{14}$.

The mean hospital stay in the probiotics group was $10.33 \pm 5.4$ days, and in the breast milk group, $7.72 \pm$ 5.41 days; the difference was not statistically significant. Statistical analysis of weight gain in between groups was not performed because no study population gained weight until their discharge.

No studied newborns gained weight (between two groups) until discharge. The finding of 'no weight gain' in this study can be explained in various ways- while developing sepsis or feeding intolerance, or due to 
prematurity itself, newborn remains on IV fluid containing glucose and electrolytes only. Even after starting feeds IV fluid is continued until the feed reaches at least $75 \%$ of total daily fluid requirement. This fluid strategy cannot meet the total expected calorie and nutrition requirement of the newborn. It is practically difficult to provide a newborn with expected daily calorie and nutrition in the existent NICU set up and hence they remain in a catabolic state.

\section{Conclusion \& Recommendation:}

From the present study it can be concluded that Probiotics does not reduce nosocomial sepsis and feeding intolerance in low birth weight newborns. But it reduces death of LBW babies particularly in the lower weight category. Still, it is very difficult to comment on this because the sample size was small, study period was short and randomization was not done. Further multicenter studies are needed involving larger sample size.

\section{References:}

1. Polin R A, Denson S, Brady M T. Strategies for prevention of health care-associated infections in the NICU. Pediatrics 2012; 129(4):1085-93.

2. Clark R, Powers R, White R, Bloom B, SanchezP, Benjamin B K. Jr. Nosocomial infection in the NICU: a medical complication or unavoidable problem. Journal of Perinatology 2004; 24(6): 382-88.

3. Stoll BJ, Hansen N, Fanaroff AA, Wright LL, Carlo WA, Ehrenkranz RA, et al. Late-onset sepsis in very low birth weight neonates: the experience of the NICHD Neonatal Research Network. Pediatrics 2002; 110(2): 285-91.

4. Sivanandan S, Soraisham A S, Swarnam K.Choice and duration of antimicrobial therapy for neonatal sepsis and meningitis. Int J Pediatr 2011; 48(3): 125-30.
5. Deshpande G, Rao S, Patole S. Probiotics for prevention of necrotising enterocolitis in preterm neonates with very low birthweight: a systematic review of randomised controlled trials. The Lancet 2007; 369(9573):1614-20.

6. Josef N. Gastrointestinal development and meeting the nutritional need of premature infants. Pediatrics 2007; 85(2): 629-34.

7. Laura K. How Probiotics Work; [accessed 4 Dec 2012]. Available from: http://www.ehow.com/how-does_5137299_ probioticswork.html

8. Nacie C.Probiotic Effects; [accessed 9 Sep 2012]. Available from: http://www.ehow.com/about_5426722_probiotic-effects.html

9. Nair V, Soraisham A S. Probiotics and Prebiotics: Role in Prevention of Nosocomial Sepsis in Preterm Infants. Int J Pediatr 2013; 67(2): 85-91.

10. Samanta M, Sarkar M, Ghosh P, Ghosh Jk, Sinha Mk, Chatterjee S. Prophylactic probiotics for prevention of necrotizing enterocolitis in very low birth weight newborns. Journal of Tropical Pediatrics 2009; 55(2):128-31.

11. Dani C, Biadaioli R, Bertini G, Martelli E, Rubaltelli FF. Probiotics feeding in prevention of urinary tract infection, bacterial sepsis and necrotizing enterocolitis in preterm infants. Biol Neonate 2002; 82: 103-8.

12. Hu XY, Zhou YX, Xu SZ, Lin YY. Effect of probiotics on feeding intolerance in low birth weight premature infants. Chinese Journal of Contemporary Pediatrics 2010; 12(9): 693-5.

13. Lin CH, Su BH, Chen AC, LinTW, Tsai CH, The TF, Oh W. Oral probiotics reduce the incidence and severity of Necrotising Enterocolitis in very low birth weight infants. Pediatrics 2005; 115(1): $1-4$.

14. $\mathrm{XY}$ vs $\mathrm{XX}$, which chromosome is more superior and stronger? [ accessed 27 Sep 2014]. Available from: https://answers. yahoo.com/ question/index? qid=200903120 12844AAb3Qd4 